\title{
Scanning Electron Microscopy Characterization of Carbon Steel Fractured by Pressure while Exposed to Cryogenic Temperatures.
}

\author{
M. W. Pendleton* and C. Mazzella**
}

* Microscopy and Imaging Center, Texas A\&M University, Biological Sciences Building Room Number 119, Mail Stop 2257, College Station, TX. 77843-2257

** Wild Well Control, Inc./Blowout Tools, Inc., 2202 Oil Center Court, Houston, TX. 77073

Wild Well Control, Inc./Blowout Tools, Inc. (Wild Well/BTI) conducts safety training in safe pipe freezing techniques. Pipe freezing is a method of blocking a pipe for maintenance or repair used in many oilfield applications. A heat exchanger, such as a fluid tight metal jacket that surrounds the pipe to be isolated, is filled with liquid nitrogen which cools the pipe. At the start of the freezing process, water begins to freeze inside the pipe near the heat exchanger attached to the outer pipe surface. As freezing continues, ice in the cooled area of the pipe will grow axially until a plug forms at the center line of the heat exchanger. Further cooling results in a growth of ice along the axial plane away from the center-line in both directions until a stable ice plug with concave ends is formed. The Wild Well/BTI safety training addresses the concerns directly related to safe pipe freezing techniques. The concern that the ice plug may slip in the pipe has been tested in both laboratory tests and field situations. If the proper procedures are followed, an adhesive bond is formed at the boundary between the metal pipe and the ice plug in the same manner as water adhering to metal in freezing temperatures [1]. The concern that the pipe will be altered by pipe freezing have been tested by metallurgical laboratories and major petroleum companies which, for various grades and sizes of pipe, report that the pipe properties are unchanged following controlled freezing techniques [2]. The careful monitoring of temperatures during pipe freezing by Wild Well/BTI prevent the metal in ferric steel pipe from undergoing the ductile to brittle transition [3] which could cause pipe failure.

During the Wild Well/BTI safety training course, a demonstration of deliberate pipe failure is performed to illustrate the consequences of improper pipe freezing procedures. While it is known that the water pressure in the pipe increases after the ice plug is formed [4], the increasing hydrostatic pressure in regions of unfrozen water will result in pipe failure if the water is blocked and the pressure cannot be released by venting [5]. It must be emphasized that with monitored and controlled pipe freezing techniques, such pipe failures can be avoided. The monitoring by Wild Well/BTI of pressures and temperatures inside the pipe during plug formation allows for safe and reliable pipe freezing. In order to demonstrate the mechanics of pipe bursting when proper procedures are not followed, Wild Well/BTI routinely takes pipe samples to failure following ice plug formation in training situations. The instructors then present an analysis to students of how bursting can be avoided by following approved procedures. An image of a demonstration of pipe freezing during an ice plug training exercise (Fig. 1A) shows the covering of frost on the pipe during plug formation and the wires connected to multi-point Type $\mathrm{T}$ thermocouples which monitor the freezing process. The diagram (Fig. 1B) is a cross-section of the ice plug in the pipe which is surrounded by the freeze jacket. The ice plug has not yet completely formed at the stage illustrated. Micrographs of the fracture surface of carbon steel exposed to $-62^{\circ} \mathrm{C}$ for $10 \mathrm{~h}$ during this intentional failure were produced using secondary and backscatter detectors of a JEOL JSM 6400 Scanning Electron Microscope (SEM) (30 KeV accelerating voltage, $15 \mathrm{~mm}$ working distance). Examples of features observed along the pre-planned fracture surface include crack initiation areas (Fig. 2A secondary micrograph and Fig. 2B backscatter micrograph) in the carbon steel. 
References:

[1] G. Lock, On the Freeze Occlusion of Water, pp. 199-221. In: K. Cheng and N. Seki (eds.), Freezing and Melting Heat Transfer in Engineering: Selected Topics on the Ice-Water Systems and Welding and Casting Processes, Hemisphere Publishing Corp., New York, 1991.

[2] G. Howard, Oil and Gas J. 83 (1982) 108.

[3] D. Tantam and D. Wigley, Proc. Eighth Int. Cryogenic Eng. Conf. (1980) 681.

[4] S. Aldousari, J. King Abduaziz Univ.: Eng. Sci. 15 No. 2 (2004) 61.

[5] H. Inaba, Freezing Fracture in Water Pipes, pp. 235-257. In: K. Cheng and N. Seki (eds.), Freezing and Melting Heat Transfer in Engineering: Selected Topics on the Ice-Water Systems and Welding and Casting Processes, Hemisphere Publishing Corp., New York, 1991.
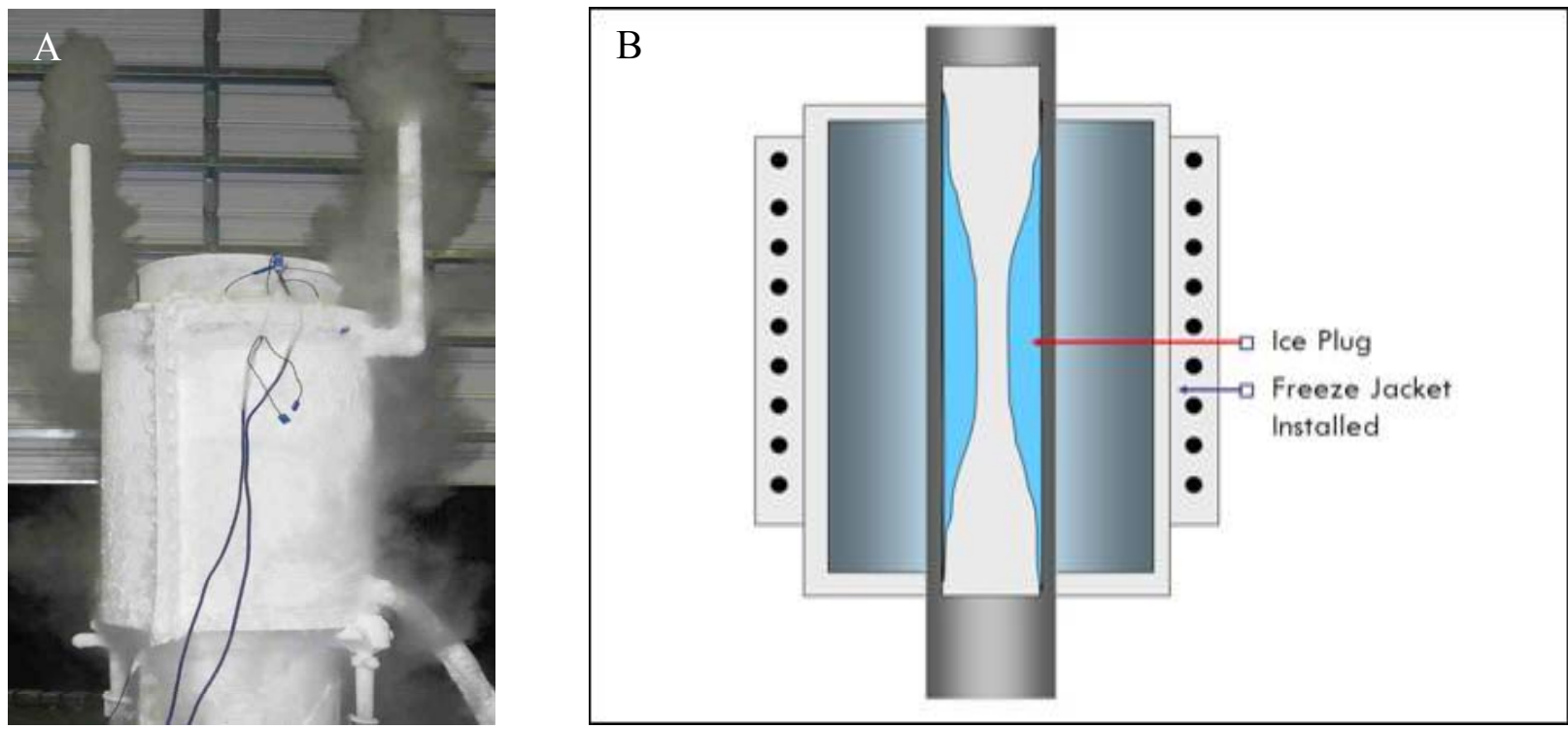

Fig. 1. Pipe freezing apparatus. A. Frost covers the pipe during plug formation and wires connect to multi-point Type T thermocouples. B. Diagram of cross-section of ice plug during freezing.
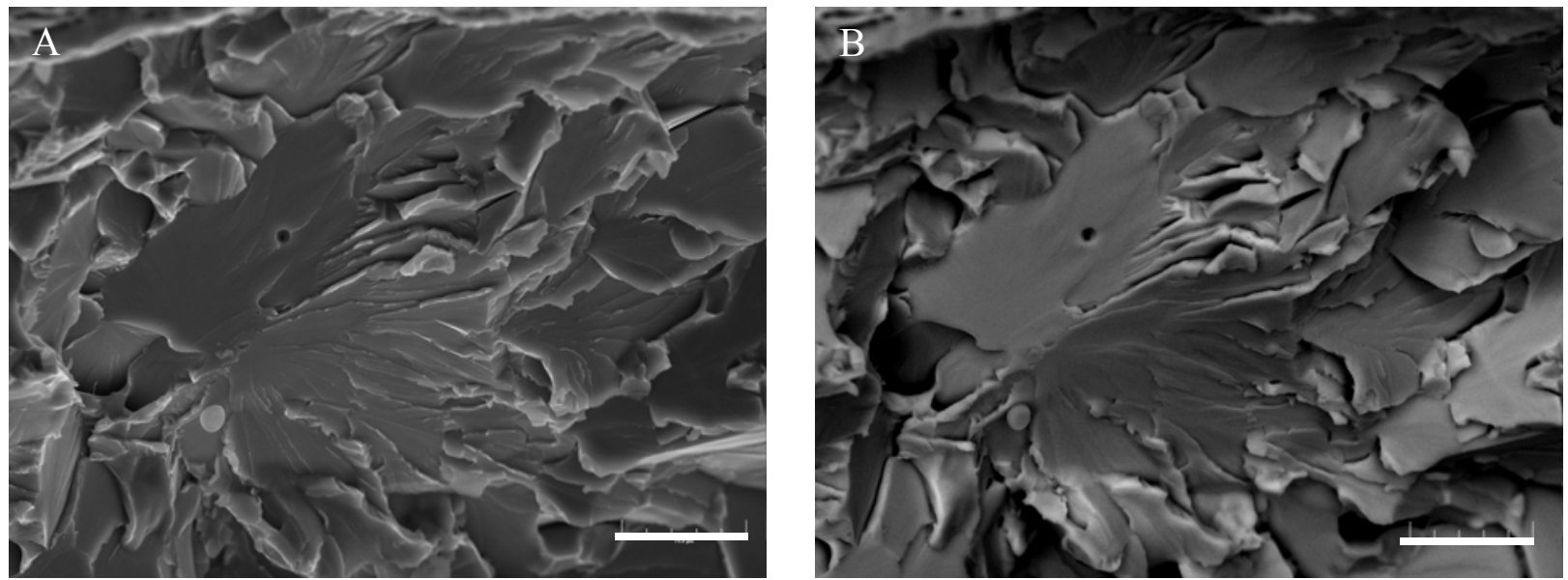

Fig. 2. Micrographs of deliberately fractured surface. A. Secondary micrograph of crack initiation area. B. Backscatter micrograph of same crack initiation area shown in Fig. 2 A. Scale bars $=15 \mu \mathrm{m}$. 